\title{
Evaluation of Extension of Blood Vessels during Static Stretching Using Ultrasound 2D Speckle Tracking Imaging
}

\author{
Hiromi Shinno $^{1}$, Satoshi Kurose ${ }^{1}$, Yutaka Yamanaka ${ }^{1}$, Yaeko Fukushima ${ }^{1}$, Hiromi Tsutsumi ${ }^{2}$, \\ Yoko Miyasaka ${ }^{4} \&$ Yutaka Kimura ${ }^{2,3}$ \\ ${ }^{1}$ Department of Health Science, Graduate School of Medicine, Kansai Medical University, Osaka, Japan \\ ${ }^{2}$ Department of Health Science, Kansai Medical University, Osaka, Japan \\ ${ }^{3}$ Health Science Center, Kansai Medical University, Osaka, Japan \\ ${ }^{4}$ Department of Cardiology, Kansai Medical University, Osaka, Japan \\ Correspondence: Hiromi Shinno, Department of Health Science, Graduate School of Medicine, Kansai Medical \\ University, 2-5-1 Shinmachi, Hirakata, Osaka, 573-1010, Japan. Tel: 81-72-804-2821.
}

Received: March 28, 2017 Accepted: April 22, 2017 Online Published: April 28, 2017

doi:10.5539/gjhs.v9n8p1 URL: https://doi.org/10.5539/gjhs.v9n8p1

\begin{abstract}
Background: During static stretching, a muscle extends longitudinally, and blood vessels seem to extend simultaneously. However, it is difficult to visualize, and few findings have seen. The recent progress with ultrasonography enables measurements of movement in vivo using $2 \mathrm{D}$ speckle tracking imaging, as well as detailed evaluation of extension in tissues at the same site. The aim of this study is to evaluate longitudinal extension of blood vessels during static stretching using this methodology.
\end{abstract}

Methods: Participants were 10 healthy female volunteers (age of 39.4 \pm 11.6 ). They extended their right wrist with elbow extended. Then the ulnar artery was measured by using $2 \mathrm{D}$ speckle tracking imaging with a general-purpose ultrasound instrument. Tissue extension per unit time at the stretching site was calculated from before stretching to maximum of stretching. Simultaneous changes in the caliber of blood vessels during stretching were measured using ultrasound M-mode.

Results: The maximum angle of wrist extension was 0 to $83.6 \pm 12.5^{\circ}$. The muscle extended by $3.80 \pm 1.65 \%$ per unit time during stretching, and blood vessels simultaneously extended by $3.20 \pm 1.96 \%$. These changes were significant compared to measurements before stretching $(\mathrm{p}<0.01)$ and shows the correlation between muscles and blood vessels $(\mathrm{r}=0.56, \mathrm{p}=0.1)$. The calibers of blood vessels per unit time before and during stretching were $2.24 \pm 0.27$ and $1.64 \pm 0.53 \mathrm{~mm}$ with a significant decrease during stretching $(\mathrm{p}<0.01)$.

Conclusions: Imaging of static stretching showed extension of both the muscle/skeletal system and blood vessels longitudinally. The finding suggests that endothelial function might be activated by mechanical stress on vascular endothelial cells.

Keywords: 2D speckle tracking, static stretching, longitudinal strain, M-mode, endothelial function

\section{Introduction}

There have been several reports that static stretching improves the arterial stiffness of blood vessels (Nishiwaki, Yonemura, Kurobe, \& Matsumoto, 2015; Yamato et al., 2016). Improvement of vascular endothelial function by stretching might occur via two mechanisms: shear stress (Chien, 2007; Davies, 1995) increased by an increase in blood flow velocity during stretching, and activation of endothelial function by mechanical stress on blood vessels (Azuma, Ohhashi, \& Sakaguchi, 1980; Ohhashi, Azuma, \& Sakaguchi, 1979). Increased shear stress on endothelial cells is thought to occur when intravascular space is reduced by extended blood vessels (Fisher, Bell, \& White, 2005; Poole, Musch, \& Kindig, 1997; Supinski, Bark, Guanciale, \& Kelsen, 1986), which results in an increase in blood flow to maintain the same blood volume (Ando \& Kamiya, 1993; Yamamoto et al., 2003). The higher shear stress simultaneously increases production of nitric oxide (NO) from endothelial cells (Maeda et al., 2001), induces flaccid vascular smooth muscle, and inhibits production of vasoconstriction of smooth muscle (Furchgott, \& Zawadzki, 1980; Kuchan, \& Frangos, 1994; McDaniel, Kwon, Hill, Marshall, \& Corbett, 1996). The blood vessel wall is thought to extend under stress produced by increased blood pressure; that is, radial extension 
of blood vessels. However, upon stretching of a muscle, blood vessels are extended longitudinally. Therefore, there is a need to evaluate longitudinal extension of blood vessel walls to determine the impact of muscle stretching on blood vessels.

In ultrasound 2-dimension (2D) speckle tracking imaging used in analysis of cardiac wall motion, image patterns (appearance) specific to an ultrasonically confirmed region of interest (ROI) are recognized as speckles to track changes in the location of the ROI. This new method enables continuous evaluation of detailed changes in a specific region (Fig.1). The variable (peak global strain) of tissue in the ROI calculated using the method can show changes in contraction or dilation in regional myocardium, and the change can be expressed as a percentage (Langeland et al., 2005; Leitman et al., 2004; Ogawa et al., 2006).

During static stretching, a muscle extends longitudinally and blood vessels running parallel to the muscle also extend. To date, differences in oxygen saturation and muscle blood flow, and extension of muscles or muscle-tendon junctions have been measured during and after stretching, but it is difficult to visualize extension of blood vessels. Therefore, the current study was performed with the aim of evaluating longitudinal extension of blood vessels during static stretching using ultrasound 2D speckle tracking imaging.

\section{Methods}

\subsection{Subjects}

The subjects were 10 healthy female volunteers of age $39.4 \pm 11.6$ years, height $155.9 \pm 2.6 \mathrm{~cm}$, weight $49.1 \pm 2.0 \mathrm{~kg}$, body fat $23.9 \pm 3.4 \%$, and body mass index (BMI) $20.3 \pm 1.4$ (Table 1). All subjects were premenopausal and non-smokers. The subjects were provided with informed consent after receiving an explanation of the study objectives, details and precautions, based on the ethical guidelines of Kansai Medical University.

Table 1. Characteristics of study subjects

\begin{tabular}{ll}
\hline Women $(\mathrm{n})$ & 10 \\
\hline Age $(\mathrm{years})$ & $39.4 \pm 11.6$ \\
\hline Height $(\mathrm{cm})$ & $155.9 \pm 2.6$ \\
\hline Weight $(\mathrm{kg})$ & $49.1 \pm 2.0$ \\
\hline Body fat percentage $(\%)$ & $23.9 \pm 3.4$ \\
\hline Body Mass Index $\left(\mathrm{kg} / \mathrm{m}^{2}\right)$ & $20.3 \pm 1.4$ \\
\hline Systolic blood pressure $(\mathrm{mmHg})$ & $114 \pm 12$ \\
\hline Diastolic blood pressure $(\mathrm{mmHg})$ & $68 \pm 10$ \\
\hline Heart Rate $(\mathrm{bpm})$ & $61 \pm 7$ \\
\hline
\end{tabular}

Results are expressed as means \pm SD.

\subsection{Body Composition}

Body composition was measured based on height, weight, BMI and \% body fat. Weight and \% body fat were measured using an In Body 720 (Biospace Company, Seoul, Korea).

\subsection{Method of Stretching}

The central right forearm on the palmar side was stretched with the forearm placed in a mid-position, fingers extended, and the upper arm fixed. The subjects were requested to actively draw their fingertips downward until the maximum dorsal flexion of the wrist was obtained with the elbow joint placed in an extended position. This stretching was performed over about $2 \mathrm{~s}$. For quantitative evaluation of stretching, the maximum angle of the wrist in dorsal flexion was measured with the radius and second bone of the middle finger used as the standard and moving axes, respectively, using a Tokyo University joint goniometer (Tsutsumi, Co., Chiba, Japan).

\subsection{D Speckle Tracking Imaging}

Moving images of extension of the muscle and ulnar artery during static stretching were recorded for digital preservation. The images were evaluated by $2 \mathrm{D}$ speckle tracking imaging using a general-purpose ultrasound imaging instrument (Vivid 7 Dimension, GE Healthcare Japan, Tokyo, Japan). All measurements were performed by one clinical vascular technologist certified by the Japanese Association of Medical Technologists. The moving 
images were transferred to a workstation (Echo PAC PC Version1109) for off-line analysis of strain rate. Extension of the ulnar artery was traced manually and the width of the ROI was adjusted to be consistent with that in the images. Then, based on the longitudinal global strain curve obtained from tracking (Fig.1), the peak strain was measured to calculate the \% extension per unit time of the blood vessel in the upper part of the image in Fig. 2 and that of the blood vessel proximal to the extended muscle in the lower part of the image. \% extension of the muscle per unit time was calculated using the same method. Mean values for both datasets were used in the analysis. The caliber of blood vessels was measured in Motion (M)-mode before and during stretching using the leading edge-to-leading edge method to calculate changes by dividing the longest diameter by the minor radius (Fig. 4). Measurements of extension were performed per unit time over $2 \mathrm{~s}$ from commencement of extension to the time when the maximum dorsal flexion of the wrist was obtained, due to the limitation of the 2D speckle tracking analysis software.

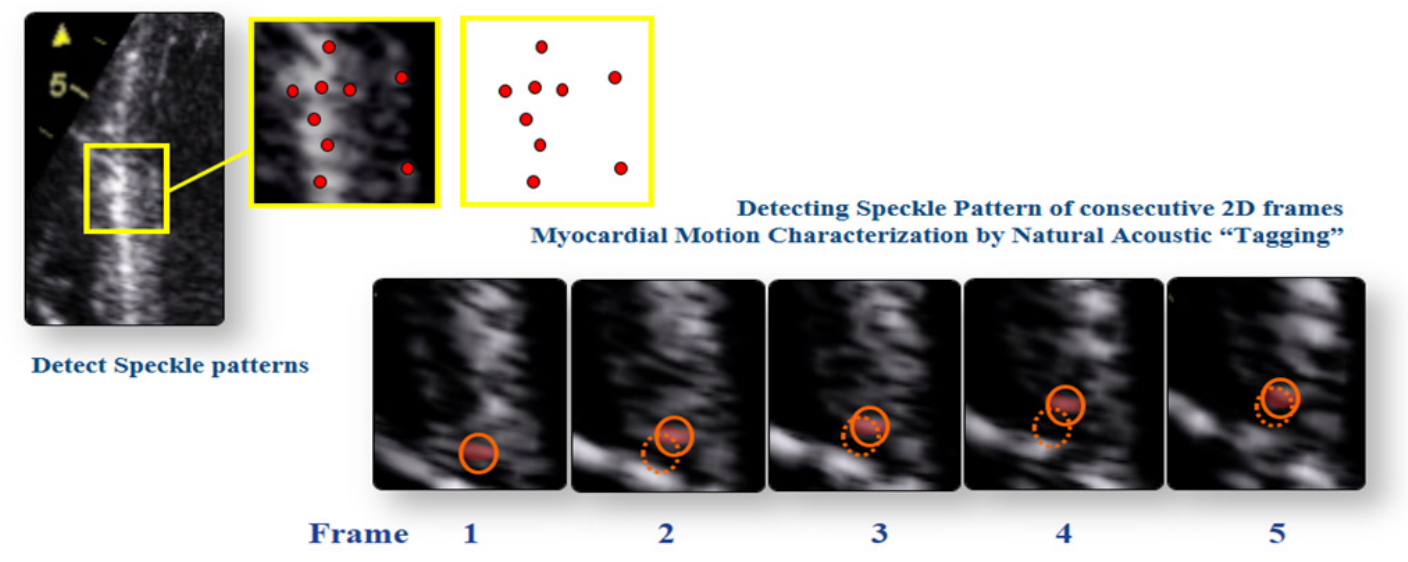

Figure 1. Principle of speckle tracking 2D

Within the myocardium of the heart echo image, small echogenicity (speckle) is to form a specific pattern for each site. Between temporally close different frames (Frame1 5), automatically searched (pattern matching method) similar pattern to detect the motion of the myocardium. By repeating this operation, to track the movements of the heart muscle continuously.

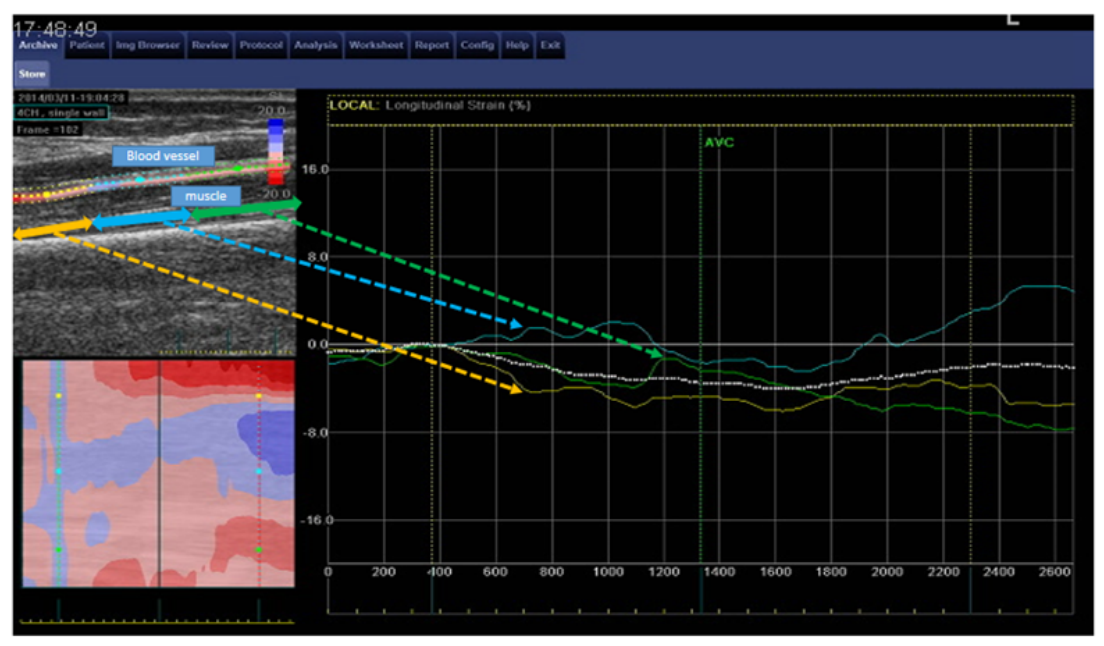

Figure 2. Example of analysis process of longitudinal deformations by 2D speckle tracking echography

It is an analysis photo of blood vessel elongation at stretching. The figure on the right is the deformation ratio of the initial length of the blood vessel. Longitudinal strain corresponding to the three (yellow, blue, green) segments. These representative cases demonstrate a negative deformation during systole, and positive deformations during diastole in the longitudinal direction. A longitudinal strain rate was brought by matching 
region of interest with the vessel diameter. The lower left shows the extension of each colored point. The vertical axis shows the longitudinal strain rate, and the horizontal axis shows time process about two seconds.

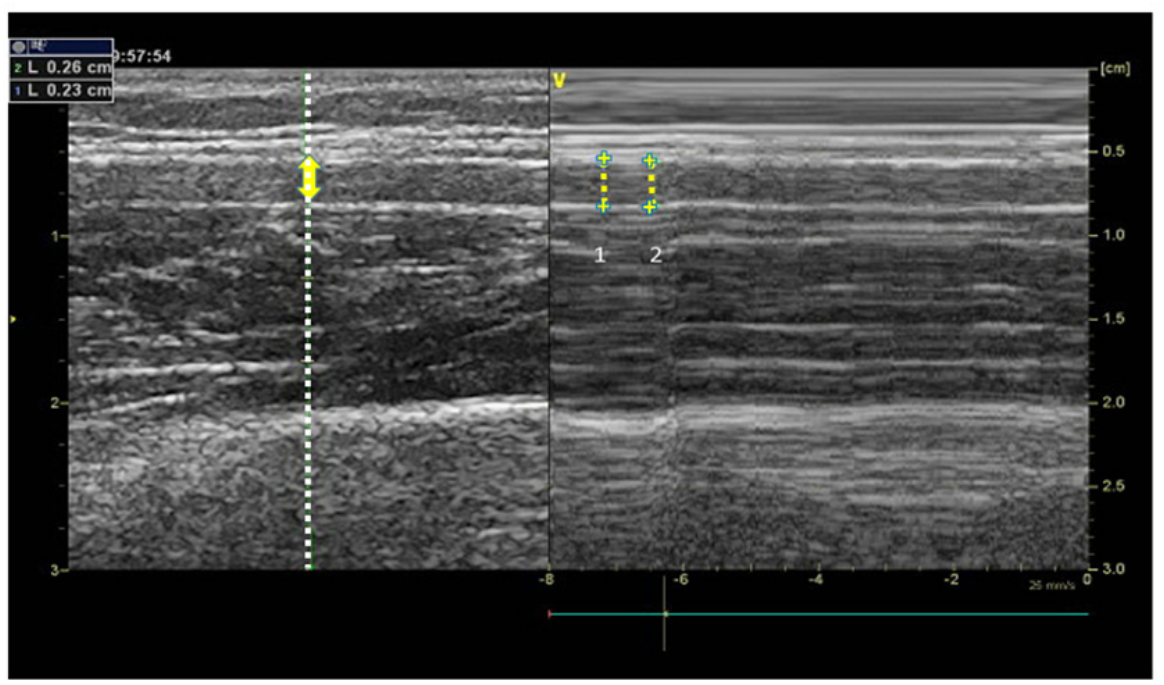

Figure 4. Example of analysis process of M-mode

Indicating the diameter of the blood vessel in two seconds measurement. 1 represents the minimum value of the vessel diameter. 2 represents the maximum value of the vascular diameter. The photo on the left shows the blood vessel during stretching. Vertical lines are points where the diameter of a blood vessel was measured. On the right shows the change of vessel diameter. Vertical axis shows the vessel diameter, the horizontal axis shows time. Numerical value of the upper left is the calculated blood vessel diameter. 1 shows the minimum and 2 shows the maximum.

\subsection{Statistical Analysis}

All data are presented as mean \pm standard deviation. Data obtained before and after stretching were compared by Wilcoxon signed rank sum test and Spearman rank correlation analysis in SPSS19.0 J for Windows, with $\mathrm{P}<0.05$ considered to be significant.

\section{Results}

All subjects were able to perform stretching with the maximum range of movement in the central right forearm on the palmar side over a period of about $2 \mathrm{~s}$, and extensions of muscles and blood vessels were recorded using ultrasound 2D speckle tracking imaging.

The maximum angle of the wrist in dorsal flexion was 0 to $83.6 \pm 12.5^{\circ}$. The extension per unit time was $3.80 \pm 1.65 \%$ for muscles and $3.20 \pm 1.96 \%$ for blood vessels (Table 2). The extension of muscles and blood vessels showed a tendency to be correlated ( $\mathrm{r}=0.56, \mathrm{p}=0.1$ ) (Figure 3$)$. The calibers of blood vessels per unit time measured in ultrasound M-mode before and during stretching were $2.24 \pm 0.27 \mathrm{~mm}$ and $1.64 \pm 0.53 \mathrm{~mm}$, respectively, and the change of $-26.8 \%$ upon stretching was significant $(p<0.01)$ (Table 2). There was no significant correlation between the $\%$ radial reduction of the caliber of blood vessels and longitudinal extension of blood vessels during stretching. 
Table 2. Extension of the muscles and blood vessels at maximum angle of the wrist in dorsal flexion

\begin{tabular}{|c|c|c|c|c|}
\hline & baseline & stretching & & $\mathrm{p}$ value \\
\hline Dorsal flexion of the wrist (degree) & 0 & $83.6 \pm 12.5$ & & - \\
\hline Extension of muscles (\%) & 0 & $3.80 \pm 1.65$ & & - \\
\hline $\begin{array}{l}\text { Longitudinal extension of blood vessels (\%) } \\
\text { (muscle opposite side) }\end{array}$ & 0 & $2.69 \pm 2.61$ & & - \\
\hline $\begin{array}{l}\text { Longitudinal extension of blood vessels (\%) } \\
\text { (muscle side) }\end{array}$ & 0 & $3.72 \pm 1.91$ & n.s & - \\
\hline $\begin{array}{l}\text { Longitudinal extension of blood vessels (\%) } \\
\text { (mean value) }\end{array}$ & 0 & $3.20 \pm 1.96$ & & - \\
\hline Caliber of blood vessels (mm) & $2.24 \pm 0.27$ & $1.64 \pm 0.53^{* *}$ & & 0.01 \\
\hline
\end{tabular}

Results are expressed as means $\pm \mathrm{SD}$.

Asterisks show statistically significant difference $\left({ }^{* *} \mathrm{p}<0.01\right)$.

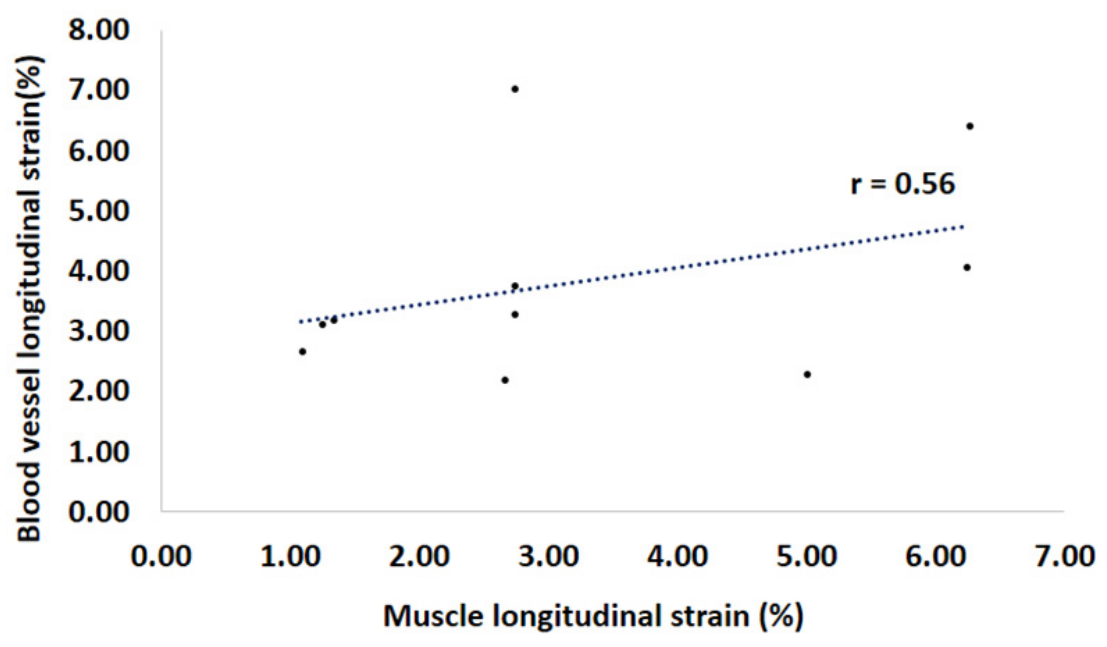

Figure 3. Muscle and blood vessel longitudinal strain correlation

\section{Discussion}

This is the first study to evaluate longitudinal extension of blood vessels per unit time during static stretching using ultrasound 2D speckle tracking imaging. We also evaluated extension of skeletal muscles in the stretching area using 2D speckle tracking imaging and the caliber of blood vessels in the same area with ultrasound M-mode.

All measurements were performed by one clinical vascular technologist certified by the Japanese Association of Medical Technologists. There was a case in which the blood vessel moved during extension, but we analyzed the clear image that was visible at the same position several times. Regarding measurement of the blood vessel diameter, data were stored as a moving image and it was possible to advance the frame in the work station (Eco pack). Measurements were made consistently at the end of systole or diastole to ensure that data were collected at the same position. During stretching of the central forearm on the palmar side, the maximum angle of the wrist in dorsal flexion changed from 0 to $83.6 \pm 12.5^{\circ}$ and resulted in almost complete extension of muscle in stretching for about $2 \mathrm{~s}$. At that time, the longitudinal extensions of muscles and blood vessels were $3.80 \pm 1.65 \%$ and $3.20 \pm 1.96 \%$, respectively, and these data showed a tendency for a correlation $(\mathrm{r}=0.56, \mathrm{p}=0.1)$. This suggests that a similar extension mechanism might occur in the ulnar artery running parallel to the muscle in the central forearm on the palmar side during static stretching. In contrast, there was no significant correlation between the $\%$ radial reduction of the caliber of blood vessels in M-mode and longitudinal extension of blood vessels during stretching. This might be because longitudinal extension of blood vessels during stretching is due to simple mechanical stress, whereas 
inner pressure of blood flow might be involved in radial extension (Ando, \& Kamiya, 1993; Cui, Blaha, Moradkhan, Gray, \& Sinoway, 2006; Maiorana, O'Driscoll, Taylor, \& Green, 2003; Takeda et al., 2006), which would be inconsistent with a simple correlation.

Visualization of extension of blood vessels has commonly been difficult. 2D speckle tracking imaging enables detection of changes in wall motion at a site of the cardiac muscle and is useful for evaluation of cardiac function. This is a new ultrasonic method that recognizes image patterns specific to an ultrasonically confirmed ROI as speckles to track changes in the location of the same ROI, enabling continuous evaluation of changes in a specific region. In evaluation of cardiac function using this method, a time-deformation (strain) curve is used to express the \% reduction of myocardium of the left ventricle in the end-diastole phase, compared to the initial length. The peak global strain in the tissue ROI reflects the change in contraction or dilation in regional myocardium and is expressed as a percentage (Langeland et al., 2005; Leitman et al., 2004; Ogawa et al., 2006). Radial and longitudinal reduction or extension of cardiac muscle can be directly and accurately evaluated with no angle dependence (Amundsen et al., 2006), which is a disadvantage of the tissue Doppler method. For cardiac function, the time-strain curve, which shows the \% reduction from the initial length in left ventricular wall motion, is obtained from 2D images of cardiac muscle, but the method also allows measurements in the abdomen, peripheral blood vessels, head, and transesophageal region. The ultrasound $2 \mathrm{D}$ speckle tracking imaging is a tool for quantitatively evaluating contraction of the left ventricular myocardium, vascular evaluation has few new attempts However, there are reports (Cameli et al., 2010; Saraiva et al., 2010) that are also used to evaluate the left atrium, which is also applied to thin structures without thickness. The ulnar artery was viewed as an image enlarged from the actual size at the time of digital preservation.

We judged that analysis was possible as for the left atrium using ultrasound 2D speckle tracking imaging. In this study, detailed changes of tissues in blood vessels during static stretching were visualized in images and the extension of these vessels was evaluated.

For improvement of vascular endothelial function, shear stress produced by increased blood flow that acts on the endothelium and mechanical stress in extension stimulation are related. Sheer stress and extension stimulation may induce similar changes in vascular endothelial cells, since both effects result in reorganization and changes in form of actin filaments and inhibition of apoptosis in the vascular endothelium. Actin filament is increased 30 minutes after loading of shear stress on vascular endothelial cells and is organized 10 minutes after loading of extension stimulation (Jin, Mitsumata, Yamane, \& Yoshida, 2002 ; Liu, Ensenat, Wang, Schafer, \& Durante, 2003). Based on these findings, stretching may be a new mechanism that has a positive effect on endothelial cells, in addition to the conventional mechanisms of improvement of vascular endothelial function, such as increased blood flow and shear stress.

Naruse et al. reported that an increase of vascular endothelial cells was promoted at extension of 5\% or more in isolated endothelial cells (Naruse, Yamada, \& Sokabe, 1998). However, extension in the current study was only $3.20 \pm 1.96 \%$. In a study in crural muscle in rat, muscle blood flow decreased when the muscle was extended, but the blood flow volume differed depending on the measurement site, even in a single muscle (Wisnes \& Kirkebø, 1976). Muscle blood flow has also been found to vary depending on the degree of stretching for congeners of human lower extremities (Kagaya \& Muraoka, 2005). In muscle with high extension of the fascicle length, the extension of intramuscular blood vessels and reduction of the caliber of blood vessels are high, causing limitation of blood flow. Depending on the relationship between joint and muscle, the maximum stretching angle and extension vary. A difference in extension is likely to inhibit intramuscular circulation, contributing to promotion of the circulatory response. In this study, the central forearm on the palmar side (ulnar flexor muscle of the wrist) was measured, and the mean maximum angle of the wrist in dorsal flexion was $83.6 \pm 12.5^{\circ}$, which was higher than the reference angle $\left(70^{\circ}\right)$. Since muscles of the forearm support each other in a complex manner, findings similar to those for the lower extremities may be observed when different sites are examined.

There are several limitations in this study. First, there is a time-related limitation, in which the rate of longitudinal strain for about $2 \mathrm{~s}$ was analyzed in a period equivalent to 1 heartbeat in the analysis software, although the general-purpose ultrasonic imaging instrument used in our evaluation does allow evaluation of peripheral blood vessels. Second, only the central forearm on the palmar side was used for tracking to ensure easy fixation and visualization. Although stretching was performed for $2 \mathrm{~s}$ until the maximum angle was obtained from commencement of stretching, an error in the duration of stretching might increase extension of muscles and blood vessels. Thus, measurements at sites with larger maximum angles in the joint movable range or a larger amount of muscle are required in future studies. 


\section{Conclusion}

This study was performed with the aim of evaluating longitudinal extension of blood vessels during static stretching, using ultrasound 2D speckle tracking imaging. Visualization of the extension of blood vessels in the images allowed calculation of extension and changes in the caliber of blood vessels. Static stretching was found to cause longitudinal extension in both muscles and blood vessels, and there was a significant difference between the calibers of blood vessels before and during stretching. Extension of blood vessels during muscle stretching is an important finding that suggests that endothelial function may be activated by mechanical stress of vascular endothelial cells during this process. However, since shear stress was increased by the reduced caliber of blood vessels at the same time, determination of the impact of these findings on activation of vascular endothelial function requires further studies.

\section{Funding}

Funding was from institutional sources only.

\section{Authors' Contributions}

SH collected data and drafted the manuscript. KS, YY, FY, TH performed experiments and assisted in writing the manuscript. KY supervised the study and finalized the manuscript.

\section{Declaration of Conflict of Interest}

None of the authors have a conflict of interest regarding the contents of this report.

\section{Acknowledgements}

We are grateful to Mr. Toshio Sato and Mr. Saburo Yamanaka (GE Healthcare Japan), and Mr. Yasuhiro Kasuga, a clinical vascular technologist, for their assistance and support.

\section{References}

Amundsen, B. H., Helle-Valle, T., Edvardsen, T., Torp, H., Crosby, J., Lyseggen, E., ... Slørdahl, S. A. (2006). Noninvasive myocardial strain measurement by speckle tracking echocardiography: validation against sonomicrometry and tagged magnetic resonance imaging. Journal of the American College of Cardiology, 47(4), 789-93.

Ando, J., \& Kamiya, A. (1993). Blood flow and vascular endothelial cell function. Frontiers of Medical \& Biological Engineering, 5(4), 245-64. PMid:8136312

Azuma, T., Ohhashi, T., \& Sakaguchi, M. (1980). An approach to pathogenesis of "white finger" induced by vibratory stimulation: Acute but sustained changes in vascular responsiveness of canine hindlimb to noradrenaline. Cardiovascular Research, 14(12), 725-30. PMid:7260966. https://doi.org/10.1093/cvr/14.12.725

Cameli, M., Lisi, M., Mondillo, S., Padeletti, M., Ballo, P., Tsioulpas, C., Bernazzali, S., \& Maccherini, M. (2010). Left atrial longitudinal strain by speckle tracking echocardiography correlates well with left ventricular filling pressures in patients with heart failure. Cardiovascular Ultrasound, 8, 14. PMid:20409332 PMCid:PMC2868789. https://doi.org/10.1186/1476-7120-8-14

Chien, S. (2007). Mechanotransduction and endothelial cell homeostasis:the wisdom of the cell. American Journal of Physiology. Heart and Circulatory Physiology, 292(3), H1209-24.

Cui, J., Blaha, C., Moradkhan, R., Gray, K., \& Sinoway, L. (2006). Muscle sympathetic nerve activity responses to dynamic passive muscle stretch in humans. The Journal of Physiology, 576(pt2), 625-634. PMid:16873399 PMCid:PMC1890351. https://doi.org/10.1113/jphysiol.2006.116640

Davies, P. F. (1995). Flow-mediated endothelial mechanotransduction. Physiological Reviews, 75(3), 519-60. PMid:7624393 PMCid:PMC3053532

Fisher, J. P., Bell, M. P., \& White, M. J. (2005). Cardiovascular responses to human calf muscle stretch during varying levels of muscle metaboreflex activation. Experimental Physiology, 90(5), 773-81. PMid:16049058. https://doi.org/10.1113/expphysiol.2005.030577

Furchgott, R. F., \& Zawadzki, J. V. (1980). The obligatory role of endothelial cells in the relaxation of arterial smooth muscle by acetylcholine. Nature, 27-288(5789), 373-6. [PubMed]

Jin, X., Mitsumata, M., Yamane, T., \& Yoshida, Y. (2002). Induction of human inhibitor of apoptosis protein-2 by shear stress in endothelial cells. Federation of European Biochemical Societies Letters, 529(2-3), 286-92. 
https://doi.org/10.1016/S0014-5793(02)03361-6

Kagaya, A., \& Muraoka, Y. (2005). Muscle architecture and its relationship to muscle circulation. International Journal of Sport and Health Science, 3(Special_Issue_2005), 171-180.

Kuchan, M. J., \& Frangos, J. A. (1994). Role of calcium and calmodulin in flow-induced nitric oxide production in endothelial cells. American Journal of Physiology, 266, C628-36. PMid:8166225

Langeland, S., D'hooge, J., Wouters, P. F., Leather, H. A., Claus, P., Bijnens, B., \& Sutherland, G. R. (2005). Experimental validation of a new ultrasound method for the simultaneous assessment of radial and longitudinal myocardial deformation independent of insonation angle. Circulation, 112(14), 2157- 62. PMid:16203928. https://doi.org/10.1161/CIRCULATIONAHA.105.554006

Leitman, M., Lysyansky, P., Sidenko, S., Shir, V., Peleg, E., Binenbaum, M., Kaluski, E., Krakover, R., \& Vered, Z. (2004). Two-dimensional strain-a novel software for real-time quantitative echocardiographic assessment of myocardial function. Journal of the American Society of Echocardiography, 17(10), 1021-9. PMid:15452466. https://doi.org/10.1016/j.echo.2004.06.019

Liu, X. M., Ensenat, D., Wang, H., Schafer, Al, \& Durante, W. (2003). Physiologic cyclic stretch inhibits apoptosis in vascular endothelium. FEBS Letters, 541, 52-6. https://doi.org/10.1016/S0014-5793(03)00285-0

Maeda, S., Miyauchi, T., Kitayama, T., Sugawara, J., Iemitsu, M., Irukayama-Tomobe, Y., ... Matsuda, M. (2001). Effects of exercise of 8 weeks and detraining on plasma levels of endothelium-derived factors, endothelin-1 and nitric oxide, in healthy young humans. Life Sciences, 69(9), 1005-16. https://doi.org/10.1016/S0024-3205(01)01192-4

Maiorana, A., O'Driscoll, G., Taylor, R., \& Green, D. (2003). Exercise and the nitric oxide vasodilator system. Sports Medicine, 33(14), 1013-1035. PMid:14599231. https://doi.org/10.2165/00007256-200333140-00001

McDaniel, M. L., Kwon, G., Hill, J. R., Marshall, C. A., \& Corbett, J. A. (1996). Cytokines and nitric oxide in islet inflammation and diabetes. Proceedings of The Society for Experimental Biology and Medicine, 211(1), 24-32. PMid:8594615. https://doi.org/10.3181/00379727-211-43950D

Naruse, K., Yamada, T., \& Sokabe, M. (1998). Involvement of SA channels in orienting response of cultured endothelial cells to cyclic stretch. American Journal of Physiology, 274, H1532-8. PMid:9612360

Nishiwaki, M., Yonemura, H., Kurobe, K., \& Matsumoto, N. (2015). Four weeks of regular static stretching reduces arterial stiffness in middle-aged men. Springerplus, 555. https://doi.org/10.1186/s40064-015-1337-4

Ogawa, K., Hozumi, T., Sugioka, K., Matsumura, Y., Nishiura, M., Kanda, R., Abe, Y., Takemoto, Y., Yoshiyama, M., \& Yoshikawa, J. (2006). Usefulness of automated quantitation of regional left ventricular wall motion by a novel method of two-dimensional echocardiographic tracking. American Journal of Cardiology, 98(11), 1531-7. https://doi.org/10.1016/j.amjcard.2006.06.060

Ohhashi, T., Azuma, T., \& Sakaguchi, M. (1979). Effects of microvibration on the activity of ureteral and portal smooth muscles. American Journal of Physiology, 236(5), C192-201. PMid:443363

Poole, D. C., Musch, T. I., \& Kindig, C. A. (272). In vivo microvascular structural and functional consequences of muscle length changes. American Journal of Physiology, H2107-14. PMid:9176275

Saraiva, R. M., Demirkol, S., Buakhamsri, A., Greenberg, N., Popović, Z. B., Thomas, J. D., \& Klein, A. L. Left Atrial Strain Measured by Two-Dimensional Speckle Tracking Represents a New Tool to Evaluate Left Atrial Function. Journal of The American Society of Echocardiography, 23, 172-80. PMid:20152699. https://doi.org/10.1016/j.echo.2009.11.003

Supinski, G. S., Bark, H., Guanciale, A., \& Kelsen, S. G. (1986). Effect of alterations in muscle fiber length on diaphragm blood flow. Journal of Applied Physiology, 60(5), 1789-96. PMid:3710994

Takeda, H., Komori, K., Nishikimi, N., Nimura, Y., Sokabe, M., \& Naruse, K. (2006). Bi-phasic activation of eNOS in response to uni-axial cyclic stretch is mediated by differential mechanisms in BAECs. Life Sciences, 79(3), 233-239. https://doi.org/10.1016/j.lfs.2005.12.051

Wisnes, A., \& Kirkebø, A. (1976). Regional distribution of blood flow in calf muscles of rat during passive stretch and sustained contraction. Acta Physiologica Scandinavica, 96(2), 256-66. PMid:1258671. https://doi.org/10.1111/j.1748-1716.1976.tb10194.x

Yamamoto, K., Takahashi, T., Asahara, T., Ohura, N., Sokabe, T., Kamiya, A., \& Ando, J. (2003). Proliferation, differentiation, and tube formation by endothelial progenitor cells in response to shear stress. Journal of 
Applied Physiology, 95(5), 2081-8. https://doi.org/10.1152/japplphysiol.00232.2003

Yamato, Y., Hasegawa, N., Sato, K., Hamaoka, T., Ogoh, S., \& Iemitsu, M. (2016). Acute Effect of Static Stretching Exercise on Arterial Stiffness in Healthy Young Adults. American Journal of Physical Medicine \& Rehabilitation, 95(10), 764-70, 2016. http://dx.doi.org/10.1097/PHM.0000000000000498

\section{Copyrights}

Copyright for this article is retained by the author(s), with first publication rights granted to the journal.

This is an open-access article distributed under the terms and conditions of the Creative Commons Attribution license (http://creativecommons.org/licenses/by/4.0/). 